\title{
LA ECONOMÍA PERUANA RETOMA TENDENCIAS DE CRECIMIENTO SOSTENIDO Análisis de Coyuntura
}

Dra. BEATRIZ HERRERA GARCÍA (*)

\section{RESUMEN}

El crecimiento de la economía peruana mantiene las proyecciones fijadas por el gobierno a pesar de existir flujos de capital más restrictivos provocados por la política monetaria de la Reserva Federal de los Estados Unidos (FED). Estas han elevado la tasa interbancaria de interés a 6.50 por ciento con lo que el frente externo crea un comportamiento del mercado de valores mucho más volátil, lo que tendrá impacto sobre todo en aquellos flujos de inversión de portafolio e inversiones en la bolsa de valores de la región por parte de los agentes extemos. Asimismo, los estimados del déficit en cuenta corriente de la balanza de pagos (4,3\% del PBI) no representaría mayores problemas para su financiamiento, sin perder reservas internacionales, dado que los precios de los conmodities (cobre, oro, harina de pescado), tienden a incrementarse durante el año. Igualmente todavía hay mucha libertad para que el gobierno con las metas de déficit fiscal, pactadas con el FMI hasta junio próximo, tanto la meta del sector público consolidado durante el primer trimestre, se pueda cumplir, como el 1,9 por ciento del PBI de déficit fiscal, aunque en este caso se requerirá de una mayor restricción de los gastos corrientes en el segundo semestre del año.

\section{LAS TENDENCIAS GLOBALES}

América Latina llega al siglo XXI todavía bajo los efectos negativos de las crisis financieras internacionales (asiática, rusa y brasileña) y con cierta frustración después de los esfuerzos realizados para enfrentar la problemática macroeconómica, los cuales no fueron suficientes para afrontar los otros problemas agudos por la falta de oportunidades del empleo y el incremento de la pobreza. Es más, la región en comparación con las demás regiones del mundo ha ido cediendo posiciones, pues a nivel global América Latina ocupa el quinto lugar de ingresos per cápita, ubicándose detrás de los países del sudeste asiático, de los del medio oriente y del grupo de economías en transición (ex economías socialistas).

Sin embargo, las tendencias del crecimiento mundial son contradictorias; por un lado, las condiciones internacionales mostrarían una mejora por la significativa recuperación de la economía japonesa. (Ver Cuadro $\mathrm{N}^{\circ} 1$ ), mientras que por otro lado, la economía más grande del mundo y que oferta aproximadamente un tercio de la producción mundial, Estados Unidos, sufriría una desaceleración aguda el próximo año. En cambio, los países europeos agrupados en la Zona del Euro mostrarían cierta estabilidad en su crecimiento, al igual que los países asiáticos. 
CUADRO $\mathbf{N}^{\circ}$

LA ECONOMÍA MUNDIAL: PERSPECTIVAS

(Variaciones Porcentuales)

\begin{tabular}{|c|c|c|c|}
\hline & 1999 & 2000 & 2001 \\
\hline Mundo & 2.7 & 3.7 & 3.0 \\
\hline Estados Unidos & --- & 4.7 & $2.7^{(1)}$ \\
\hline Japón & 0.6 & 2.5 & 2.5 \\
\hline Europa ${ }^{(2)}$ & $-\cdots$ & 3.5 & 3.2 \\
\hline Asia & ---- & 6.5 & 5.1 \\
\hline Perú & 3.5 & 4.8 & 5.1 \\
\hline
\end{tabular}

Fuente: Dresner Kleinnort Bencon

(1) Se espera una desaceleración aguda de la economía norteamericana en el año 2001.

(2) Países de la Zona del Euro.

Para la economía peruana estos cambios son importantes debido a la orientación geográfica de su comercio exterior dado que el 25 por ciento de las exportaciones peruanas se orientan a Asia, otro 21 por ciento a Europa y el 20 por ciento a América Latina.

Por otro lado, el mercado de capitales muestra el retorno de éstas, en el periodo de postcrisis. Además, el mercado de bonos Brady (PDI) del Perú que indica el riesgo país; es decir, el comportamiento de los "Spreads" han estado cayendo hasta el mes de marzo pasado, de esa fecha han vuelto a incrementarse indicando que el riesgo país se acrecentaría en los últimos meses, debido a las incertidumbres políticas del momento.

Sin embargo, durante el primer trimestre del 2000 los emisores de bonos latinoamericanos colocaron 15.400 millones de dólares, una cifra mucho mayor si lo comparamos con los 9.500 millones colocados en el mismo periodo de 1999.
Esta mayor demanda por títulos de la deuda latinoamericana se dio en un marco en el cual las operaciones con eurobonos superaban a las negociaciones con bonos Brady. Las negociaciones con nuevas emisiones correspondió en mayor volumen a México (que tiene vencimientos por 8.040 millones de dólares en el año 2010) seguidos de los de Brasil (con vencimientos de 5.900 millones de dólares al año 2020) ${ }^{(1)}$. Entre los motivos por el mayor interés de los inversionistas por esa deuda estaba la renovación del acuerdo entre Argentina y el FMI, así como la asignación por parte de la calificadora del riesgo Moody's del grado del inversión a la deuda mexicana.

Es de advertir que tras la moratoria de la deuda rusa, el costo del financiamiento internacional se elevó considerablemente,

(1) El volumen de las transacciones de la deuda de los mercados emergentes en el primer trimestre del 2000 fue el más elevado desde la crisis financiera rusa de agosto de 1998. 
llegando a casi en un 15 por ciento anual, :assa que disminuyó en forma paulatina a 10,5 por ciento (abril de 1999) para luego mantenerse en 12 por ciento el año pasado después de leves fluctuaciones, estas tasas la reflejaban la percepción de alto riesgo de realizar inversiones en el país y en la región, así como también el alza de las tasas de interés internacionales.

\section{EL COMPORTAMIENTO DEL PRODUCTO BRUTO INTERNO PERUANO}

Después de experimentar los efectos negativos, a lo largo de 1998 y a inicios de 1999, de los diversos shocks exógenos (crisis financieras internacionales y fenómeno climático de El Niño), los indicadores macroeconómicos de crecimiento de la economía peruana muestran una etapa de lenta recuperación durante 1999 y de una recuperación sostenida del crecimiento en el primer trimestre del 2000.

Esta tendencia reciente de la economía peruana, que se observa en el Cuadro $\mathrm{N}^{\circ} 2$; tiene como causa la diversa actividad económica de los sectores productivos, y con una recuperación muy marcada de los sectores claves de la demanda laboral: manufactura, comercio y construcción.

En enero del 2000, el PBI registró un crecimiento del 5,7 por ciento con respecto al nivel del mismo mes del año anterior. La producción de los sectores no primarios aumentó 9,4 por ciento sustentado en la recuperación del resto de la industria

CUADRO N 2

PERU: PRODUCTO BRUTO INTERNO

(Variación Porcentual)

\begin{tabular}{|l|r|r|c|c|c|}
\hline & & \multicolumn{4}{|c|}{2000} \\
\cline { 3 - 6 } SECTORES & 1999 & ENERO & FEBRERO & MARZO & ENE.MAR \\
\hline AGROPECUARIO & 12.1 & -2.6 & 5.8 & 5.10 & 3.1 \\
Agrícola & 14.0 & -7.7 & 7.2 & 6.5 & 2.9 \\
Pecuario & 7.9 & 5.4 & 3.5 & 1.9 & 3.6 \\
\hline PESCA & 66.3 & -4.3 & -14.9 & 255.6 & 67.5 \\
\hline MINERÍA & 10.0 & 0.5 & 5.3 & -1.5 & 1.3 \\
Minería & 18.3 & 6.3 & 10.4 & 1.0 & 5.8 \\
Petróleo y gas & -7.8 & -14.6 & -8.2 & -8.6 & -10.6 \\
\hline MANUFACTURA & 7.6 & 16.2 & 18.5 & 26.4 & 20.6 \\
Procesado de Rec. & 22.7 & 8.6 & 7.5 & 58.1 & 25.3 \\
Primarios & 6.3 & 19.5 & 22.7 & 14.2 & 18.7 \\
Resto de Industria & -12.3 & 4.7 & 8.4 & 0.1 & 4.1 \\
\hline CONSTRUCCIÓN & -0.5 & 7.2 & 8.9 & 12.4 & 9.6 \\
\hline COMERCIO & 1.5 & 3.9 & 4.5 & 5.3 & 4.3 \\
\hline OTROS SERVICIOS & & & & & \\
\hline PRODUCTOBRUTO & 3.8 & 5.7 & 8.6 & 11.4 & 8.6 \\
\hline INTERNO & & & & & \\
\hline
\end{tabular}

Fuente: BCR, Boletín Semanal No 10 y 18. 
$(19,5 \%)$, el comercio $(7,2 \%)$ y la construcción $(4,7 \%)$. Por su parte, la presencia de otros sectores primarios tuvo un comportamiento leve $(0,9 \%)$.

\subsection{Análisis de los sectores más dinámicos}

En enero, la producción del sector manufacturero registró un crecimiento de 16,2 por ciento. La producción de la industria procesadora de recursos primarios aumentó 8,7 por ciento, mientras que la del sector de la industria creció 19,5 por ciento. (Ver Cuadro No2).

El crecimiento del subsector industria procesadora de recursos primarios, refleja principalmente, el incremento del nivel de producción de las siguientes ramas: refinación de metales no ferrosos, conservas y productos congelados de pescado y azúcar. La producción del azúcar se explica por la mayor disponibilidad de caña de azúcar y la recuperación de los rendimientos a niveles mundiales.

La producción de harina de pescado se explica por la menor disponibilidad de otras especies como jurel, caballa entre otros. En cambio, la producción de conserva y productos congelados de pescado contó con mayor disponibilidad de sardina y pota.

Por su parte, la refinación de metales no ferrosos aumentó debido a la mayor producción de las minas Doe, Run, Cyprus y la refinería de Cajamarquilla (en enero Southerm Perú Cooper Corporation. registró un menor nivel de producción de Cobre Blister).

La producción del resto de la industria, continuará con la recuperación observada desde setiembre pasado, los grupos que registran los mayores incrementos fueron: industria del hierro y acero $(66 \%)$, industria del papel (33\%), productos metálicos, maquinarias y equipo (24\%), productos químicos, caucho y plásticos $(21 \%)$, alimentos bebidas y tabaco (11\%), textil y cuero $(9 \%)$.

La producción del grupo alimentos, bebida y tabaco, reflejó el comportamiento positivo de las ramas tabaco, alimentos diversos, bebidas gaseosas y alimentos para animales. La producción del grupo textil y cuero refleja la recuperación de la rama hilados, tejidos y acabados (que viene registrando resultados positivos desde octubre pasado). Del mismo modo, la producción de tejidos de punto, la producción de la industria de papel y cartón aumentaron en forma ligera, debido a la mayor actividad de las principales empresas de esta rama. La producción de envases de papel y cartón también aumentó. La producción del grupo productos químicos, caucho y plástico creció en la producción de la rama química industrial, asociada a su vez a la mayor producción de fibras artificiales con destino al mercado externo. La producción de productos farmacéuticos, de tocador y limpieza aumentó, destinándose la mayor parte del último producto al mercado externo. La producción del plástico se incrementó debido, principalmente, al aumento sostenido de la demanda derivada de la industria de bebidas gaseosas, tanto por los mayores niveles de producción como por la sustitución de presentaciones (botellas de plástico por vidrio). El grupo de minerales no metálicos creció a causa de la producción de cemento ya que la producción de vidrio continuó siendo afectado por la producción sustitutiva (plásticos). La producción del grupo hierro y acero aumentó considerablemente debido a la mayor actividad de sus principales empresas, al haber incrementado los volúmenes de exportación de sus principales productos. El incremento de la producción del grupo productos metálicos, maquinarias y equipo se debió a la mayor 
producción de productos metálicos por la mayor demanda derivada de productos alimenticios y de conservas de pescado; en cambio, la de maquinarias y equipos diversos disminuyó; por su parte, los de los subgrupos maquinarias eléctrica diversa, la de suministro eléctricos y la de material de transporte aumentaron.

En enero, el sector construcción registró un crecimiento de 4,7 por ciento debido principalmente a los mayores despachos locales de cemento por la recuperación de la construcción de viviendas en provincias y a la realización de diversas obras públicas y privadas. Asimismo, la valorización del avance físico de carreteras creció en términos reales, como consecuencia de los mayores desembolsos presupuestados.

\subsection{Evolución de los principales sectores en el mes de marzo}

La PBI (producción bruta interna), en marzo, creció a una tasa de 11,4 por ciento, la más alta del trimestre acumulando un crecimiento de 8,6 por ciento en el período enero-marzo del 2000 , debido al aumento de la producción de los sectores primarios $(7,9 \%)$ y a la de los sectores no primarios $(9,1 \%)$.

En el mes de marzo, todos los sectores, con excepción de la minería registraron resultados positivos destacando nuevamente el crecimiento de la manufactura $(26,7 \%)$ y la pesca $(255,6 \%)$ (Ver Cuadro $\left.N^{\circ} 2\right)$.

El sector pesca registró un crecimiento muy elevado, luego de haber tenido resultados negativos en enero y febrero, debido a la mayor extracción para consumo industrial, principalmente de anchoveta. La pesca destinada al consumo industrial registró una expansión de 637,5 por ciento en marzo, lo que se explica por la mayor extracción de anchoveta (3.480\%) que ascendió a 1752000 TM, lo cual representa el nivel más alto registrado desde mayo de 1972.

Cabe señalar que la mayor extracción de anchoveta se reportó en la zona centronorte del país donde hubo 23 días útiles de pesca, mientras que en marzo de 1999 no se permitió la extracción de anchoveta en esa zona.

En marzo, la producción del sector manufacturero registró un crecimiento de 26,7 por ciento. La proveedora de recursos primarios creció en 58,1 por ciento, mientras que la del resto de la industria aumentó en 14,2 por ciento. El resultado del subsector procesador de recursos primarios refleja el incremento del nivel de producción de todos los recursos que lo conforman (refinación de metales no ferrosos, harina de pescado, conservas y productos congelados de pescado y azúcar), con excepción de conservas y productos congelados de pescado que disminuyó debido a la menor disponibilidad de sardinas para conservas; la producción de azúcar aumentó debido a la mayor disponibilidad y el mejoramiento de la calidad de la caña. La producción de harina de pescado se incrementó sustantivamente por la mayor disponibilidad de anchoveta. Cabe indicar que las 400 mil toneladas de harina de pescado producidas es la segunda cifra más alta después del registrado en marzo de 1971 (456 mil toneladas). La refinación de metales ferrosos aumentó debido a la mayor producción de las minas Doe Run, Cyprus y la refinación de Cajamarquilla. La producción de petróleo refinado se mantuvo constante.

En la producción del resto de industria destacó la mayor producción del grupo de alimentos, bebidas y tabaco debido al comportamiento positivo de las ramas de bebidas gaseosas y alimentos diversos, lo que fue parcialmente contrarrestado por el 
resultado negativo de las ramas cerveza, molinera y productos lácteos. La producción del grupo textil y cuero aumentó como consecuencia de la recuperación de la rama hilados, tejidos y acabados, y el aumento de la producción de tejidos de punto. La producción de la industria de papel aumentó por el crecimiento de la industria de papel y cartón, y de las ramas de envases de papel y cartón debido a la mayor demanda de cajas para leche evaporada. La mayor producción del grupo productos químicos, caucho y plástico se explica por el incremento en la producción de la rama química industrial, en la de productos farmacéuticos, de productos de tocador y limpieza, en la producción de caucho y plásticos debido a la mayor demanda derivada de la industria de bebidas gaseosas. En la producción del grupo minerales no metálicos destacó la producción de cemento y de vidrio. La producción del grupo industria del hierro y acero aumentó al haberse incrementado los volúmenes de exportación. El grupo productos metálicos, maquinarias y equipo registró un significativo aumento debido a la mayor elaboración de productos metálicos por la mayor demanda de envases para alimentos, asimismo, aumentaron de maquinarias y equipos diversos y la de suministros eléctricos. Finalmente, la producción de industria diversas se expandió considerablemente ante la incorporación de una nueva empresa y la recuperación de otros.

En marzo, el sector construcción registró una variación leve del 0,1 por ciento respecto al mismo mes del año anterior, en el cual registró una contracción del 14,5 por ciento con lo que el sector acumuló un incremento del 4,1 por ciento durante el primer trimestre del 2000.

La producción del sector agropecuario tuvo un aumento del 5,0 por ciento el mes de marzo, reflejando el incremento de la producción agrícola $(6,5 \%)$, y en menor medida la producción pecuaria $(1,9 \%)$. La mayor producción agrícola se debió al creciente cultivo de papa y maíz amarillo duro, asociado con mejores condiciones climáticas y la adecuada disponibilidad de agua. El subsector pecuario registró creció en un 1,9 por ciento destacando la mayor producción de leche que se explica por las inversiones en adquisición de ganado lechero, así como por la mayor disponibilidad del forraje, y las mayores compras por parte de las gobiernos locales.

\section{LA BALANZA COMERCIAL EN EL PERIODO ENERO-MARZO DEL 2000}

En el primer trimestre del 2000, el déficit de la balanza comercial peruana ascendió a 139 millones de dólares, mayor en 5 millones al registrado en similar período del año anterior. Las exportaciones totalizaron 1647.9 millones de dólares con un incremento de 16,5 por ciento, en cambio las importaciones totales alcanzaron los 1787.1 millones de dólares, con un incremento de 15,4 por ciento. (Ver Cuadro $\mathrm{N}^{\circ} 3$ ). 
CUADRON 3

PERÚ: BALANZA COMERCIAL

(En millones de dólares)

\begin{tabular}{|c|c|c|c|c|c|c|c|}
\hline & \multicolumn{3}{|c|}{2000} & & \multicolumn{3}{|c|}{ ENERO - MARZO } \\
\hline & ENE & FEB & MAR & 1999 & 2000 & FLUJO & VAR. $\%$ \\
\hline BALANZA COMERCIAL & -23.7 & -49.8 & -65.7 & -133.8 & -139.3 & -5.5 & -4.1 \\
\hline Exportaciones fob(1) & 564.8 & 520.8 & 562.3 & 1415.0 & 1647.0 & 232.9 & 16.5 \\
\hline I. Productos Tradicionales & 377.6 & 350.0 & 399.7 & 972.3 & 1127.7 & 155.4 & 16.0 \\
\hline Mineros & 262.8 & 248.6 & 292.7 & 762.2 & 804.1 & 41.9 & 5.5 \\
\hline Petróleos, derivados & 27.6 & 25.9 & 37.5 & 55.7 & 91.0 & 35.3 & 63.4 \\
\hline Agrícolas & 6.9 & 5.9 & 10.9 & 10.8 & 23.7 & 12.8 & 118.5 \\
\hline Pesquero & 80.3 & 69.7 & 58.7 & 143.6 & 209.0 & 65.4 & 45.5 \\
\hline II. Productos No Tradicional & 166.5 & 165.9 & 156.8 & 425.7 & 489.3 & 63.6 & 14.9 \\
\hline Agropecuarios & 46.2 & 34.3 & 22.7 & 94.8 & 103.2 & 8.3 & 8.8 \\
\hline Textiles & 52.2 & 55.5 & 55.0 & 124.9 & 162.7 & 37.9 & 30.3 \\
\hline Pesqueros & 14.0 & 16.4 & 17.7 & 52.7 & 48.1 & -4.6 & -8.7 \\
\hline Metal-mecánicos & 4.8 & 5.1 & 5.4 & 15.1 & 15.3 & 0.2 & 1.3 \\
\hline Químicos1 & 15.0 & 17.4 & 19.4 & 46.8 & 51.8 & 5.0 & 10.7 \\
\hline Sidero-metalúrgicos & 17.9 & 21.0 & 16.6 & 38.7 & 55.6 & 16.9 & 43.8 \\
\hline Minerales no metálicos & 2.7 & 3.3 & 3.6 & 13.1 & 9.6 & -3.5 & -26.5 \\
\hline Otros & 13.7 & 13.0 & 16.4 & 39.7 & 43.1 & 3.3 & 8.4 \\
\hline III.Otros & 20.3 & 4.9 & 5.7 & 17.0 & 30.9 & 13.9 & 81.6 \\
\hline Importaciones fob(1) & 588.5 & 570.6 & 628.0 & 1548.8 & 1787.1 & 238.3 & 15.4 \\
\hline Bienes de consumo & 92.9 & 113.1 & 128.2 & 350.7 & 334.2 & -16.5 & -4.7 \\
\hline Insumos & 271.7 & 281.3 & 279.5 & 641.3 & 831.9 & 190.6 & 29.7 \\
\hline Bienes de capita & 1208.3 & 160.8 & 201.4 & 514.1 & 570.6 & 56.5 & 11.0 \\
\hline Otros bienes & 16.1 & 15.5 & 18.9 & 42.8 & 50.6 & 7.8 & 18.2 \\
\hline
\end{tabular}

Fuente: BCR, Boletín Semanal No 19, Cuadros Nros. 40, 41, 42, 43 y 44.

(1) Libre a bordo (Free on board).

\section{CUADRO N 4}

ESTRUCTURA PORCENTUAL DE LAS EXPORTACIONES

(En porcentaje)

\begin{tabular}{|l|r|r|r|r|r|}
\hline & \multicolumn{3}{|c|}{ 2000 } & \multicolumn{2}{c|}{ ENERO - MARZO } \\
\hline Productos & ENE & \multicolumn{1}{|c|}{ FEB } & \multicolumn{1}{c|}{ MAR } & $\mathbf{1 9 9 9}$ & $\mathbf{2 0 0 0}$ \\
\hline Mineros & 46.5 & 47.7 & 57.1 & 53.9 & 48.8 \\
\hline Petróleos, derivados & 4.9 & 5.0 & 6.7 & 3.9 & 5.5 \\
\hline Agrícolas & 1.2 & 1.1 & 1.9 & 0.8 & 1.4 \\
\hline Pesqueros & 14.3 & 13.4 & 10.4 & 10.1 & 12.7 \\
\hline 1. Tradicionales & 66.9 & 67.2 & 71.1 & 68.7 & 68.4 \\
\hline 2. No Tradicionales & 29.5 & 31.9 & 27.9 & 30.1 & 29.7 \\
\hline 3. Otros & 3.9 & 0.9 & 1.0 & 1.2 & 1.9 \\
\hline Total (1+2+3) & 100.0 & 100.0 & 100.0 & 100.0 & 100.0 \\
\hline
\end{tabular}

Fuente: Elaboración propia en base a cifras del BCR. 


\section{CUADRO N ${ }^{\circ} 5$}

TÉRMINOS DE INTERCAMBIO

(Año $1990=100$ )

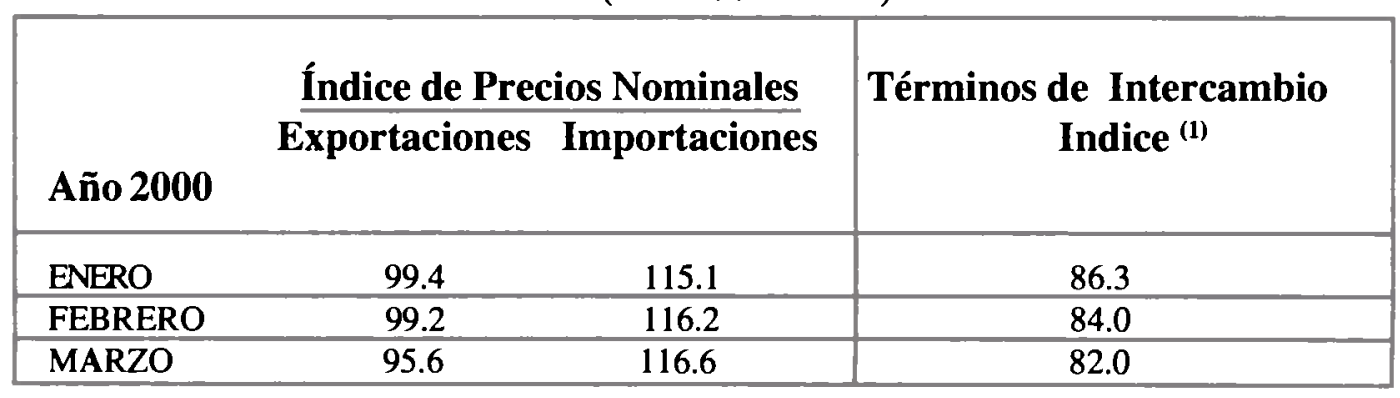

Fuente: Elaboración propia en base a cifras del BCR.

(1) Índice de los Precios de las Exportaciones / Indice de los precios de las importaciones.

El comercio exterior peruano es deficitario, fundamentalmente, por depender de las exportaciones denominadas tradicionales, entre los cuales destacan dos grupos de productos: mineros $(48,8 \%)$ y pesqueros $(12,7 \%)$.

En otras palabras, el comercio exterior peruano está constituido por exportaciones de productos primarios en un 68,4 por ciento (Ver cuadro $\mathrm{N}^{\circ} 4$ ). Esta estructura exportadora hace altamente dependiente a la economía de producción externa cuyos precios tienen tendencias asimétricas a las de las exportaciones por lo que las tendencias de intercambio de comercio exterior son desfavorables al Perú. En enero, febrero y marzo del 2000 el intercambio desigual fue de 86,$3 ; 84,0$ y 82.0 respectivamente. (Ver Cuadro $\mathrm{N}^{\circ}$ ).

La balanza comercial registró un déficit en los meses del enero ( -23.7 millones de dólares), febrero ( -49.8 millones) y marzo (-65.7 millones de dólares), acumuló en el primer trimestre del 2000 un déficit comercial de 139 millones de dólares, mayor en 5.5 millones comparado con similar periodo del año anterior. (Ver cuadro $N^{\circ} 3$ ).

Las exportaciones totales en el periodo de análisis alcanzaron los 1.647 millones de dólares, con una tasa de crecimiento del 16,5 por ciento mientras que las importaciones ascendieron a 1.782 millones de dólares con una tasa de crecimiento de 15,4 por ciento.

En enero, las exportaciones fueron de 564.8 millones de dólares, cifra mayor a la de enero del año anterior, debido el aumento de las exportaciones no tradicionales, destacando los productos textiles, sidero-metalúrgico y agropecuarios, contrarrestadas en forma parcial por las menores rentas de productos tradicionales.

Las exportaciones tradicionales alcanzaron los 378 millones de dólares, cifra menor en 4 millones $(1,0 \%)$ a la del mismo mes el año anterior, las rentas al exterior de los sectores pesqueros, petróleo y agrícola aumentaron en 20, 6 y 3 millones de dólares, respectivamente.

Por su parte, el sector minero disminuyó sus embarques al exterior en 32 millones de dólares. Las exportaciones no tradicionales lograron 167 millones de dólares mayores en 25 millones (17\%) a los de enero del año anterior. Las exportaciones agropecuarias sumaron 46 millones de dólares, debido principalmente a las mayores exportaciones de mango, espárrago, harina de flores de marigold y los demás productos de origen animal. Por su parte, las exportaciones textiles alcanaron los 52 millones de dólares, 
debido principalmente a las mayores exportaciones de prendas de vestir y fibras textiles, en cambio las exportaciones pesqueras se redujeron en 2 millones de dólares por las menores exportaciones de concha de abanico y langostinos. Las exportaciones de productos químicos sumaron 15 millones de dólares debido a las mayores exportaciones de botellas y frascos de plástico, penicilina y sus derivados, etc. Las exportaciones de productos siderometalúrgicos alcanzaron los 18 millones de dólares, debido a los mayores embarques de aleaciones de zinc por parte de la refinería de zinc de Cajamarquilla. En cambio, las exportaciones de productos metalmecánicos se redujeron por las menores ventas de motocicletas Honda del Perú. Por su parte, el rubro de otros, registró ventas al exterior por 14 millones de dólares, debido a las mayores exportaciones de madera y papel, principalmente.

En marzo, las exportaciones tradicionales alcanzaron los 400 millones de dólares, registrando un aumento del 18 por ciento respecto a similar mes de 1999 , debido principalmente a las mayores exportaciones mineras (oro, cobre, zinc, plomo, estaño y hierro), estos registraron un incremento de 50 millones de dólares. Por su parte, las exportaciones de petróleo totalizaron 37 millones de dólares debido al incremento de los precios promedio de exportación del crudo, así como de las exportaciones de derivados. En cambio, el aumento de las exportaciones de productos pesqueros en 15 millones de dólares se debió al incremento de las exportaciones de harina de pescado en condiciones de precios menores ante la debilidad de la demanda de Europa y Asia. Las exportaciones tradicionales agrícolas totalizadoras 11 millones de dólares debido, principalmente, a los mayores embarques de azúcar.
En marzo del 2000, las exportaciones no tradicionales totalizaron 157 millones de dólares, aumentado 7 por ciento respecto al mismo mes del año anterior, que se explica por los mayores embarques de productos textiles ( 8 millones de dólares), siderometálúrgicos ( 3 millones de dólares) y otros (1 millón de dólares). Las exportaciones textiles totalizaron 55 millones de dólares, cifra mayor en 8 millones de dólares al de marzo del año anterior, debido principalmente a las mayores exportaciones de prendas de vestir (T-Shirts) y fibras textiles. Las exportaciones de productos siderometalúrgicos sumaron 17 millones de dólares, debido a los mayores embarques de alambres de cobre y productos de zinc. Las exportaciones de los productos del rubro otros llegó a 16 millones de dólares, debido a las mayores rentas de madera y papel.

En el primer trimestre del 2000 , las importaciones ascendieron a 1,787 millares de dólares monto superior en 228 millones a las registrados durante el primer trimestre del año anterior.

En marzo, las importaciones aumentaron 17 por ciento con relación a similar mes de 1999, las importaciones ascendieron a 587 millones de dólares (Ver Cuadro $\mathrm{N}^{\circ}$ 3 ), que se explica principalmente por las mayores importaciones de materias primas $(28,1 \%)$, de bienes de capital $(9 \%)$ y las menores importaciones de bienes de consumo no duradero se explican, fundamentalmente, por las menores compras de azúcar y arroz, mientras las menores compras de bienes de consumo duradero fueron en automóviles, juguetes y equipos de telecomunicaciones. En las importaciones de materias primas destacaron las mayores adquisiciones de combustibles, lubricantes y anexos y materias primas para la industria, las importaciones de bienes de capital aumentaron, principalmente, debido a las mayores compras de bienes de capital para la 
industria. El incremento en las adquisiciones de maquinaria industrial (maquinarias de ingeniería civil y equipos para determinadas industrias) explica el 83 por ciento del aumento de los bienes industriales de capital.

En marzo, las importaciones aumentaron de la misma forma que el mes del año anterior en un 13 por ciento y sumaron 628 millones de dólares (Ver cuadro N³). Esto se debe, principalmente, por las mayores importaciones de materias primas $(18,1 \%)$, bienes de capital $(26,7 \%)$ y las menores compras de bienes de consumo $(-0,6 \%)$. Las menores importaciones de los de consumo no duradero se explican por las menores compras al exterior de arroz, azúcar y productos lácteos, mientras que las mayores compras de bienes de consumo duradero responden a la mayor importación de productos electrodomésticos, y vehículos de transporte. En las altas compras externas de materias primas destacaron las adquisiciones de materias primas para la industria, combustibles lubricantes y (consumo). En cuanto a los insumos para la industria, se observaron crecientes compras de productos químicos farmacéuticos semielaborados. Las importaciones de bienes de capital aumentaron por los mayores cambios de equipos de transporte y materiales de construcción.
En marzo, el déficit de la balanza neta petrolera ascendió a 23 millones de dólares, mayor en 6 millones al mismo saldo negativo del año pasado, efecto provocado por los mejores precios promedio del crudo importado y de los derivados.

\section{TÉRMINOS DE INTERCAMBIO (T.I.)}

En enero, los términos de intercambio registraron un incremento del 10 por ciento respecto al mismo mes de 1999. (Ver cuadro $\mathrm{N}^{\circ}$ 5), explicado por los mayores precios promedio de las exportaciones y parcialmente compensados por los mayores precios promedio de las importaciones. El alza del índice de precios de las exportaciones se debe a los mayores precios del petróleo y derivados, cobre, zinc y plomo.

En marzo, los términos de intercambio presentaron una disminución, al igual que el mismo mes de 1999, del 3 por ciento (Ver cuadro $\mathrm{N}^{\circ} 5$ ) explicado por los mayores precios promedios de las importaciones, principalmente, del petróleo, compensado en parte por los mayores precios promedio de las exportaciones, las cuales se dieron por los mayores precios del petróleo y derivados, cobre, zinc y plomo.

GRATCA 1

FERU: TÉRAROS DE IMIEECAHLOO

Gho bue [yo - [IX]

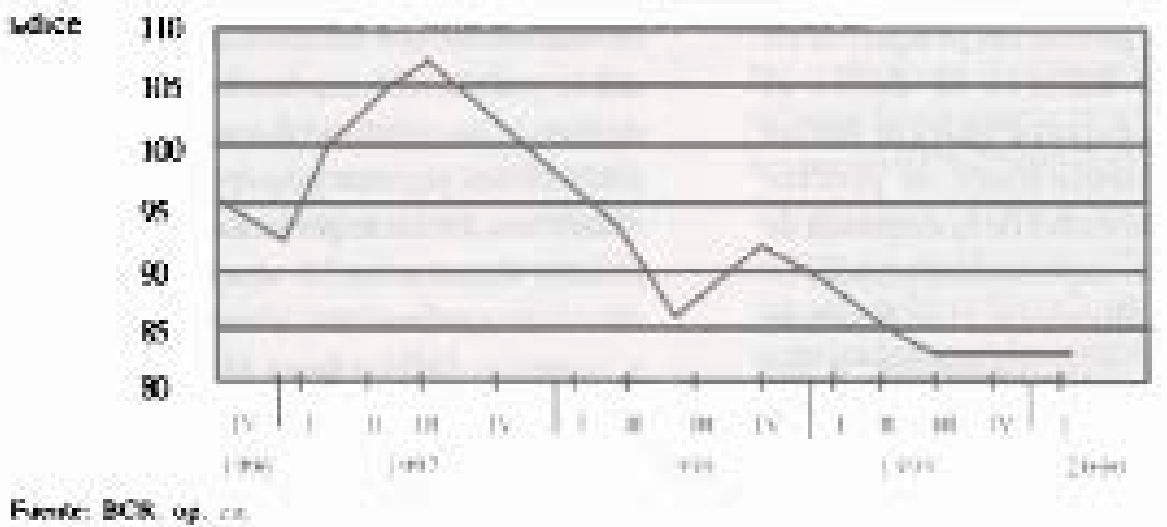


En resumen, durante el primer trimestre del 2000 los términos de intercambio se incrementaron en 2 por ciento respecto al primer trimestre del año anterior, como consecuencia del aumento de los precios promedio de exportación (11\%), compensados en parte por el incremento de los precios promedio de exportación (8\%).

En este resultado cabe destacar el incremento de los precios internacionales del cobre (26\%), zinc (15\%), estaño (2\%), oro (2\%) y petróleo $(150 \%)$.

\section{BALANZA DE PAGOS PRIMER TRIMESTRE DEL 2000}

Durante el primer trimestre, el déficit de la cuenta corriente de la Balanza de Pagos (denominado también brecha externa) fue de 485 millones de dólares, equivalente al 3,5 por ciento del PBI, y mayor en 29 millones de dólares al primer trimestre del año anterior (Ver Cuadro $\mathrm{N}^{\circ} 6$ ).

El aumento del déficit de la cuenta corriente se explica por el mayor déficit de los servicios (rubro 2) ante el aumento de los fletes y el menor ingreso neto de transferencias corrientes. La financiación del déficit correspondió, principalmente, el flujo de capitales de largo plazo del sector privado por 436 millones de dólares y del sector público por 290 millones de dólares y habiéndose registrado una salida de capitales del corto plazo de 85 millones de dólares. El mayor flujo de capitales afectó positivamente las reservas internacionales se incrementaron en 400 millones de dólares.

\section{CUADRO No 6}

\section{PERÚ: BALANZA DE PAGOS}

(En millones de dólares)

\begin{tabular}{|c|c|c|c|c|c|c|}
\hline & \multicolumn{5}{|c|}{1999} & \multirow{2}{*}{$\begin{array}{c}2000 \\
I\end{array}$} \\
\hline & I & II & III & IV & AÑ $\mathbf{O}$ & \\
\hline I. Balanza en Cuenta. Cte. & -456 & -530 & -453 & -591 & -2030 & -485 \\
\hline 1. Balanza Comercial & -134 & -194 & -106 & -166 & -600 & .139 \\
\hline a. Exportaciones & 1415 & 1412 & 1584 & 1703 & 6114 & 1648 \\
\hline b. Importaciones & -1549 & -1606 & 1690 & -1869 & -6714 & -1797 \\
\hline 2. Servicios & -101 & -120 & -134 & -109 & -464 & -115 \\
\hline a. Exportaciones & 417 & 392 & 423 & 448 & 1679 & 401 \\
\hline b. Importaciones & -518 & -512 & -557 & -557 & -2143 & -516 \\
\hline 3. Renta de factores & -398 & -388 & -375 & -473 & -1635 & -394 \\
\hline a. Privado & -277 & -225 & -228 & -309 & -1039 & -269 \\
\hline b. Público & -122 & -163 & -147 & -165 & -596 & -125 \\
\hline 4.Transferencias Ctas. & 177 & 173 & 161 & 157 & 669 & 164 \\
\hline II. Cuenta Financiera & 10 & 273 & 160 & 248 & 692 & 641 \\
\hline 1. Sector privado & 589 & 673 & 640 & 220 & 2123 & 436 \\
\hline 2. Sector público & -90 & 258 & 17 & 237 & 422 & 290 \\
\hline 3. Capitales a c/plazo & -489 & -658 & -497 & -209 & -1853 & -85 \\
\hline III.Financiamiento Excep. & -8 & 0 & 26 & 0 & 18 & 0 \\
\hline $\begin{array}{l}\text { IV.Flujo de Reservas Netas }{ }^{(\mathbf{l})} \\
\text { (Incremento con el Signo -) }\end{array}$ & 342 & 94 & 127 & 211 & 775 & -416 \\
\hline 1. Variación RIN ${ }^{(2)}$ & 361 & 118 & 77 & 224 & 780 & -400 \\
\hline 2.Monetización de oro & 19 & 24 & -50 & 13 & 5 & 16 \\
\hline V. Errores y omisiones netas & 112 & 182 & 140 & 131 & 546 & 260 \\
\hline
\end{tabular}

Fuente: BCR, Boletín Semanal Nro. 29.

(1) Se trata de reservas del BCRP, resultan de 1-2.

(2) Corresponde el saldo de las reservas internacionales. 
El principal rubro del déficit de la cuenta corriente de la balanza de pagos fueron los servicios, cuyo déficit ascendió a 115 millones de dólares, monto mayor en 14 millones al de similar periodo del año anterior debido al incremento del déficit por transportes de mercancías así como por la disminución del superávit en comunicaciones. Como se anticipó el mayor déficit por transportes se debió principalmente al incremento de los egresos de los fletes de importación.

El balance por renta de factores (rubro 3 de la cta. cte.) siempre deficitario, registró en el primer trimestre del año un déficit de 394 millones de dólares menor en 4 millones a similar periodo del año anterior; es decir, el pago de servicios financieros internacionales obedeció básicamente al menor déficit del sector privado compensado por el mayor déficit del sector público.

La cuenta financiera muestra tendencia hacia el restablecimiento financiero internacional. El balance de la cuenta financiera en el primer trimestre del 2000 muestra un saldo positivo de 641 millones de dólares (en 1998, el saldo anual fue similar al saldo del primer trimestre del año en curso). La cuenta financiera del sector privado y público ascendieron a 436 millones de dólares y 290 millones de dólares, respectivamente (Ver Cuadro $N^{\circ} 6$ ).

La cuenta financiera del sector público fue superior en 380 millones de dólares el observado en el mismo periodo de 1999. Este saldo es el resultado del pago por concepto de amortizaciones de la deuda pública del orden de 262 millones de dólares (el monto de los intereses se registra en el rubro " $b$ " de la renta de factores) así como de los ingresos provenientes de desembolsos de créditos concertado por 551 millones de dólares. Los desembolsos para proyec-tos de inversión fueron canalizados, por las empresas públicas financieras (123 millones de dólares) y por el gobierno central (120 millones de dólares).

Por su parte, el reflujo de las inversiones de cartera de portafolios que ascendieron a -1853 millones durante 1999 , tuvieron un importante retroceso durante el primer trimestre del 2000 ascendiendo su monto a tan solo -85 millones de dólares. De mantenerse esta tendencia estaría reflejando las expectativas de los inversionistas externos frente al nuevo panorama económico latinoamericano, después de una larga crisis durante los dos años anteriores.

\section{AHORRO E INVERSIÓN, DEMANDA Y OFERTA AGREGADAS}

La alta tasa de crecimiento del PBI alcanzado en el primer trimestre del 2000 , de 8,5 por ciento resultado de las tasas combinadas de crecimiento de los sectores primarios $(7,7 \%)$ y de los sectores no primarios $(9,2 \%)$ fue debido la gran parte a la recuperación de la Tasa de Inversión que ascendía a 24,2 por ciento durante el período de análisis, en el mismo periodo del año anterior la tasa de inversión fue de 22,8 por ciento del PBI (Ver cuadro $\mathrm{N}^{\circ} 7$ ). De acuerdo al modelo económico, es el sector privado el que muestra un mayor dinamismo en el proceso de inversión, en los periodos comparados bajo análisis de 18,9 por ciento (I -1999) a 20,6 por ciento del PBI (I2000), en cambio, la inversión pública disminuyó su participación a tan sólo una tasa de 3,6 por ciento del PBI.

En términos macroeconómicos, un aumento de la inversión tiene que estar sustentada, básicamente, en un incremento del ahorro interno respecto al PBI, según los datos del Cuadro $\mathrm{N}^{\circ} 7$, el ahorro interno se incrementó de 19,2 por ciento en el primer trimestre de 1999 a 20,7 por ciento en similar periodo del 2000 . 
CUADRO $\mathbf{N}^{\circ}$

TASAS DE AHORRO E INVERSIÓN

(En porcentaje del PBI nominal)

\begin{tabular}{|l|r|r|r|}
\hline & \multicolumn{2}{|c|}{1999} & $\mathbf{2 0 0 0}$ \\
\hline & I & ANO & I \\
\hline Ahorro Interno & 19.2 & 18.2 & 20.7 \\
\hline Sector Público & 3.4 & 1.7 & 1.5 \\
\hline Sector Privado & 15.8 & 16.5 & 19.2 \\
\hline Ahorro Externo & 3.6 & 3.6 & 3.5 \\
\hline Ahorro Inversión & 22.8 & 21.8 & 24.2 \\
\hline Inversión Pública & 3.9 & 4.3 & 3.6 \\
\hline Inversión Privada & 18.9 & 17.6 & 20.6 \\
\hline
\end{tabular}

Fuente: Elaboración propia sobre la base de información del BCR.

El ahorro externo que técnicamente se mide como el déficit en cuenta corriente, representó tan sólo el 3,5 por ciento del PBI lo que indica una caída o disminución leve de la brecha externa. En el primer trimestre del 2000 también se apreció una recuperación de la demanda interna que creció en dicho periodo 9,4 por ciento destacando como ya se anticipó, la expansión de la IBI (inversión bruta interna) a 16,8 por ciento.
Por otro lado, las asimetrías mostradas durante 1999 en el dinamismo de las exportaciones y de las importaciones se tornaron en forma simétrica en el primer trimestre del 2000 , en la que cabe destacar la fuerte recuperación de las importaciones cuya tasa superó el crecimiento de las exportaciones.

Entre las indicaciones macroeconómicas de la economía peruana se aprecia una

\section{CUADRO $\mathbf{N}^{\circ} 8$}

PERÚ: OFERTA, DEMANDA AGREGADA

(Variaciones porcentuales)

\begin{tabular}{|c|c|c|c|}
\hline & \multicolumn{2}{|c|}{1999} & \multirow{2}{*}{$\frac{2000}{I}$} \\
\hline & $\mathbf{I}$ & AÑO & \\
\hline I. Oferta Global & -3.5 & -0.7 & 7.9 \\
\hline 1. PBI & 1.3 & 3.8 & 8.5 \\
\hline 2. Importaciones & -20.6 & -17.3 & 5.1 \\
\hline II. Demanda Global & -3.5 & -0.7 & 7.9 \\
\hline 1. Demanda interna & -10.0 & -2.9 & 9.4 \\
\hline a. Consumo privado & -3.7 & 0.9 & 5.6 \\
\hline b. Consumo público & 0.9 & 3.2 & 11.5 \\
\hline c. IBI ${ }^{(1)}$ & -23.3 & -11.9 & 16.8 \\
\hline 2. Exportaciones & 20.3 & 6.9 & 3.6 \\
\hline
\end{tabular}

Fuente: Elaboración propia sobre la base de información del BCR.

(1) Inversión Bruta Interna. 
alta tasa de correlación entre el aumento de la inversión bruta interna y el crecimiento de las importaciones, por lo que la demanda agregada registró un incremento del 7,9 por ciento en el primer trimestre del 2000 , que se explica por el crecimiento de la demanda interna de 9,4 por ciento debido a la fuerte expansión de la inversión bruta interna que saltó a 16,8 por ciento, la recuperación de la IBI se viene observando desde el cuarto trimestre del año anterior, gracias al impulso del sector privado. 